\title{
Melodrama y mitología: imágenes de la migración en Guten Tag, Ramón y Señales que precederán al fin del mundo
}

Resumen: Este artículo revisa dos posiciones extremas observadas en la cultura mexicana al abordar el tema de la migración: una sentimental y otra abstracta; la primera está ligada a prácticas discursivas y culturales tradicionales como el melodrama, representada por la película Guten Tag, Ramón, y la segunda utiliza la mitología para reelaborar el viaje de los migrantes de manera simbólica, como se aprecia en la novela Señales que precederán al fin del mundo. Si una manipula los sentimientos, la otra ofrece como alternativa al migrante la posibilidad de reinventar su identidad simbólicamente. La oscilación entre estas dos tendencias ofrece una posibilidad de resolver el dilema entre lo interior y lo exterior, lo personal y lo social, lo real y lo simbólico, superando así la simplificación con la que generalmente se entiende la migración y permitiendo a los individuos involucrarse con el mundo y, a final de cuentas, transformarlo.

Palabras clave: melodrama, migración, mitología, identidad, trauma cultural

Hablar de desplazamiento implica necesariamente hablar de conmoción. Esta afirmación parte de la premisa de que desplazarse es una palabra mucho más cargada de sentido negativo de lo que la definición del diccionario sugiere. Desplazarse implica no solo el sacar a alguien de su lugar habitual o el trasladarse de un lugar a otro, sino que ello sucede a pesar del sujeto, debido a fuerzas externas y ajenas a su voluntad. La palabra generalmente evoca a personas que son obligadas a abandonar sus lugares de origen o de residencia debido a violencia, peligro de muerte, falta de oportunidades económicas, nula libertad sexual o religiosa, entre otras causas (cf. DiFrancesco 2011: 156). Por su parte, la palabra conmoción conlleva en su significado una fuerza emocional superior a la que sugiere su definición, según ha sido aceptada en los diccionarios, pues si el sentido denotativo de la palabra es el mismo que el que le da la RAE ("movimiento o perturbación del ánimo o del cuerpo"), su sentido connotativo está elevado a un grado mayor de intensidad. Conmocionar describe el efecto causado por un evento percibido como extremadamente doloroso, chocante, violento, ofensivo o hasta peligroso.

Rafael Hernández Rodríguez, Southern Connecticut State University

Ә Open Access. ( 2021 Rafael Hernández Rodríguez, published by De Gruyter. (c) BY This work is licensed under the Creative Commons Attribution 4.0 International License. 
Debido a la naturaleza involuntaria del desplazarse y las implicaciones emocionales y psicológicas que ello representa para los individuos, es posible hablar al mismo tiempo de un trauma, según lo define Jeffrey Prager; es decir "an event or series of events remembered as so dangerous as to be impossible to preserve an equilibrating belief in a world that presumes our presence” (Prager 2011: 429). De esta forma vemos que desplazamiento y conmoción son con frecuencia los dos estados que mejor describen la migración como trauma. Un ejemplo de este trauma puede ser ilustrado con uno de los episodios más lamentables de la historia americana contemporánea. El 6 de abril de 2018, el fiscal general de Estados Unidos, Jeff Sessions, anunció una política de cero tolerancia por parte del actual gobierno estadounidense para con los inmigrantes centroamericanos que intentaban entrar a Estados Unidos para pedir asilo como refugiados debido a la atroz situación económica y política en sus países.

Las consecuencias más inhumanas de esta política, reveladas dos meses después, fueron la separación de niños de sus padres; estos niños, algunos de los cuales eran infantes de brazos, fueron colocados en "jaulas”. Hacia el inicio del verano de 2018, el mundo leyó horrorizado las noticias de lo que sucedía en la frontera entre Estados Unidos y México, donde familias enteras eran separadas y los niños arrebatados de los brazos de sus madres para ser colocados en centros de detención, en su mayoría, cajones de metal y alambrado. La conmoción colectiva fue tal que llevó a la presentadora de la cadena de televisión MSNBC, Rachel Maddow, a romper en llanto al reportar este hecho (cf. Schmidt 2018). Si bien se supo de ello en abril, la realidad es que esta práctica había comenzado meses antes, en octubre de 2017, según reportó Caitlin Dickerson en The New York Times (cf. Dickerson 2017). A este reporte se sucedieron otros en el mismo diario y en diversos periódicos de circulación nacional, desatando una ola de protestas ciudadanas, no solo en Estados Unidos, sino alrededor del mundo.

Esta política, oficialmente llamada "Family-Separation Policy", fue duramente criticada en diversos medios por su crueldad, y tanto en los artículos y reportajes de los diarios norteamericanos, como en las fotografías y otros materiales audiovisuales que circulaban en portales de noticias en las redes sociales, se enfatizaba la crueldad de esta política, mostrando imágenes del trauma de pequeños llorando, de padres y madres tratando de no soltar a sus hijos en manos de oficiales indiferentes, de pequeños tras rejas o alambradas jugando tristemente o recostados en el piso de cemento. Todas estas imágenes tenían una intención clara: despertar la empatía de los ciudadanos. Por ello quizás no hubo otra imagen más emblemática que la fotografía de la esposa del presidente estadounidense llevando una gabardina verde oliva con la leyenda "I really don't care, do you?”, mientras subía al avión que la llevaría a Texas a “visitar” los centros de detención de infantes. Al llevar esta prenda, Melania Trump entablaba un 
diálogo con el público, intencionalmente o no, en el cual se burlaba directamente de los detractores de tan inhumana ley. ${ }^{1}$

La respuesta de la opinión pública fue tajante en condenar esta política y la indiferencia, si no crueldad, de la actual administración norteamericana, tan bien resumida en el episodio de la chaqueta verde oliva, y con frecuencia se mencionó la conmoción que las imágenes causaron. Conmoción, entonces, es una reacción de las emociones en momentos particulares de la vida que consideramos extremos; pero esta reacción puede ser también una estrategia discursiva con el fin de indicar y convencer al público de lo extremo de esa situación particular y despertar una inmediata empatía. Por ello, episodios como el de la chaqueta verde oliva, al tratarse de ataques dirigidos a un grupo en particular con ciertos aspectos comunes (etnicidad, lengua, religión, condición social, etc.), pueden ser considerados ejemplos de un trauma cultural. Un trauma cultural, en palabras de Jeffrey C. Alexander, ocurre cuando "members of a collectivity feel they have been subjected to a horrendous event that leaves indelible marks upon their group consciousness, marking their memories forever and changing their future identity in fundamental and irrevocable ways" (Alexander 2004: 1). Y este es el caso con frecuencia de lo que sucede en el proceso de migración, particularmente cuando grupos humanos considerados diferentes debido a su etnicidad, religión, "raza" o clase social intentan trasladarse a otro lugar donde no es raro que se les tilde de intrusos, ilegales, subversivos o disruptivos del orden establecido; en otras palabras, de no pertenecer, y por lo tanto, de tener poca importancia.

Este no pertenecer evidentemente funciona como mecanismo de control, pues el marcar la alteridad de dichos grupos permite excluir, demonizar y en general delimitar al otro, demarcando al mismo tiempo la propia identidad. El otro es lo que no soy yo; yo soy lo que el otro no es. El proceso, sin embargo, no es siempre en un solo sentido, pues en ocasiones puede permitir un rol más activo a los excluidos, para quienes el trauma cultural puede servir también como una manera de dar cohesión al grupo y ayudarles a redeterminar su propia identidad a partir de la segregación que sufren. O como argumentan Alon Lazar y Tal Litvak-Hirsh, es posible que "members of collectives view cultural trauma as a symbolic boundary” (Lazar / Litvak-Hirsh 2009: 183). Es decir, el trauma cultural puede ayudar a procesar el trauma individual, ya sea físico o psicológico, para redirigir las energías a defender y valorar aspectos que dan sentido a la colectivi-

1 Aunque al principio sus asistentes afirmaron que el llevar esa chaqueta no había querido decir nada, meses después la misma Melania Trump confirmó que sí había vestido esta prenda a propósito para enviar un mensaje a la prensa que, según ella, la criticaba (cf. Bruney 2018). 
dad, tales como la lengua, la religión, la etnicidad, etc. De esta forma, "symbolic boundaries could serve a certain group to place individuals, as well as entire groups, as being within or outside its social and symbolic borders" (Lazar / LitvakHirsh 2009: 184).

Por su propia naturaleza el fenómeno de la migración generalmente implica una confrontación entre el yo y el otro, y como vimos, puede también crear una dicotomía entre el individuo y la colectividad. Por ello, este artículo se propone examinar cómo esa dualidad se manifiesta en la sociedad mexicana, un país de migrantes, y los problemas tanto del trauma personal como del trauma cultural que ello puede representar. En la cultura mexicana se observan dos tendencias extremas al tocar el tema de la migración: una excesivamente sentimental, representada por la película Guten Tag, Ramón (2013) de Jorge Ramírez Suárez, y otra que, por el contrario, intenta abordar el problema de manera abstracta haciendo uso de lo simbólico, representada por la novela Señales que precederán al fin del mundo (2010) de Yuri Herrera. La primera está ligada a prácticas discursivas y culturales tradicionales como el melodrama, el cual, como lo define Linda Williams, es un modo fundamental de la sensibilidad popular, que intenta llevar al público a sentir "sympathy for the virtues of beset victims" (Williams en Singer 2001: 6). En el extremo opuesto se encuentra la representación simbólica del mismo fenómeno por medio de la mitologización. En este caso, se aborda la migración, no en términos reales y específicos, como un fenómeno de un lugar y tiempo precisos, sino como un fenómeno mítico, donde el viaje del migrante en sí no es sino una metáfora de otros viajes trascendentes o espirituales.

Si bien la migración ha sido una parte importante de la historia de México, es a la vez un fenómeno que se manifiesta de maneras distintas en diferentes lugares y en cada época. De ahí que al tratar el tema sin abordar las especificidades del momento y el lugar en que se escribe, se corre el riesgo de ignorar las experiencias reales y minimizar la urgencia de los traumas de los desplazados. Sin embargo, debido a su carga afectiva, la migración, paradójicamente, es un tema que se presta fácilmente para la apelación a las emociones de manera, a veces, superficial. Tal vez por ello, ante la sensibilidad popular del melodrama, hay un deseo de rechazar esta "simplicidad" optando por "intelectualizar" el fenómeno por medio de su mitologización. Lo que muestran las dos obras analizadas aquí son los nuevos parámetros entre los que los mexicanos oscilan al juzgar el fenómeno de la migración, el melodramático y el mitológico. Estos parámetros se erigen en los dos extremos del espectro de prácticas discursivas que permiten a los individuos involucrarse con el mundo y, a final de cuentas, transformarlo. 0 se apela a las emociones como estrategia de generar empatía o se transforma el viaje cotidiano de los desplazados en un viaje mítico, por medio del cual es posible negociar la identidad perdida y la nueva ganada. 


\section{1 (Melo)Drama del migrante: Guten Tag, Ramon}

Guten Tag, Ramón es una película mexicano-alemana que desde su estreno recibió elogios y ganó popularidad no solo entre el público mexicano, sino entre los públicos de festivales internacionales que veían con emoción el triunfo en Alemania de un joven mexicano sin recursos, y con él el de millones de desposeídos. ${ }^{2}$ También tuvo sus detractores, aquellos que veían en este filme un gran chantaje emocional, pues triunfo en este contexto significaba simplemente no morir en el intento. La película se centra en las desventuras de Ramón (Kristyan Ferrer), quien a sugerencia de su amigo Güero (Héctor Kotsifakis) decide emigrar a Alemania después de intentar varias veces sin éxito entrar ilegalmente a Estados Unidos. Sin ninguna oportunidad de empleo en su pueblo, la situación de Ramón es desesperada. Con una madre indefensa (Arcelia Ramírez) y una abuela enferma y fastidiosa (Adriana Barraza) que dependen de él, y con la constante presión de los carteles de la droga para que trabaje para ellos, Ramón se encuentra ante una realidad sin futuro. Güero le sugiere de manera casual que se vaya a Alemania y le da los datos de una tía suya que vive allá.

Por más ridícula que parece la sugerencia de Güero, la aventura lo es aún más, pues a diferencia de la frontera con Estados Unidos, que se puede cruzar a pie o nadando, emigrar a Alemania desde México implica una serie de pasos que se antojan imposibles para un muchacho en la situación en la que se encuentra Ramón. Y sin embargo, Ramón lo logra en unos pocos minutos y sin explicación lógica. El viaje de Ramón se nos presenta por medio de un montaje de cortes rápidos (cf. Ramírez Suárez 2013: 00:20). La escena comienza con un plano largo en el que vemos un autobús avanzando por un camino polvoso en una ranchería mexicana que se disuelve en una sucesión de imágenes: Ramón caminando en una ciudad, un avión despegando y aterrizando, Ramón confundido en el aeropuerto, la revisión del pasaporte por un oficial de aduanas, Ramón buscando transporte público del aeropuerto y un tren saliendo de la estación en alguna ciudad europea. Tras un corte, aparece Ramón en el tren; tras otro, vemos a Ramón con las instrucciones en la mano caminando a lo largo de un río, una mañana gris con nieve en el suelo, buscando la dirección de la tía de su amigo. En cuestión de seis minutos y sin el menor contratiempo, la película ha transportado a la audiencia, junto con

\footnotetext{
2 La película se estrenó en el Festival Internacional de Cine de Morelia y ha sido presentada en otros festivales como el Greater Washington Immigration Film Festival, el Festival Internacional du Film d'Amour - FIFA de Mons en Chile, el XX Boston Ibero American Film Festival y el Keppel Latin American Film Festival de Singapore (cf. Buen día, Ramón 13 y 25 de octubre de 2015; Festival Internacional de Cine de Morelia 2013; Latin American Film Festival Singapore 2017; Festival International du Film d’Amour - FIFA de Mons en Chile 2015).
} 
Ramón, hasta Alemania. Esta simplificación de un problema mayor no es única de esta película, como veremos más adelante; al contrario es bastante común en el cine, sobre todo por economía narrativa, pero en este caso también favorece las soluciones milagrosas o estrafalarias tan importantes en el discurso esquemático del melodrama.

La sensibilidad melodramática, cuando se aplica al tema de la migración, frecuentemente sintetiza el desplazamiento en gestos precisos: cortes que implican movimiento, un automóvil, un barco, imágenes de pies avanzando por el desierto o brazos nadando a través de un río, etc. Siguiendo pues el esquema melodramático, vemos a Ramón cruzando el Atlántico y llegando a Alemania, en una secuencia que es a la vez exagerada y sucinta y que evita que el espectador se detenga a pensar en una serie de hechos que no se explican en la película, por ejemplo, que el obtener un pasaporte en México es más un lujo que una necesidad para la mayoría de los ciudadanos, pues sacar el pasaporte lleva tiempo y requiere dinero, además de una serie de pasos como hacer cita en internet, etc. Igualmente complicado, aparte de caro, es el sacar un pasaje de avión a Europa, especialmente si se vive en una comunidad rural lejos de una ciudad, que es el caso de Ramón. Pero para la audiencia, estas cosas resultan insignificantes porque la narrativa les ha ayudado a establecer una empatía con Ramón y a desear su triunfo, aun cuando al llegar a la dirección de la tía de su amigo queda claro que sus problemas no han terminado.

Al llamar a la puerta, un hombre poco amigable abre y, molesto, le dice a Ramón en alemán primero y luego en inglés que Gloria, la tía de Güero, ya no vive ahí (cf. Ramírez Suárez 2013: 00:28). Y aquí vemos otra caracterísitica del melodrama, que depende de un histrionismo elemental. Si por medio del montaje de cortes rápidos se nos presenta el viaje trascontinental en breves minutos, de manera similar la angustia de Ramón, debida al trauma del rechazo en la nueva sociedad, es subrayada por las expresiones de impotencia en su rostro al no poder comunicarse verbalmente. En esta representación, las palabras sobran, y decir con el cuerpo es típico del melodrama porque este, según Peter Brooks, representa "a moment when the bodies behave nearly histerically, if by hysteria we understand a condition of bodily writing, a condition in which the repressed affect is represented on the body" (Brooks 1995: xi). Así, la angustia de no poder comunicarse verbalmente es subrayada por el cuerpo de Ramón, en la impotencia en su rostro pasmado y los balbuceos ante el rechazo en los encuentros con los alemanes.

Ramón se halla de pronto en la calle sin dinero y sin más opción que pedir limosna, hasta que una mujer jubilada, Ruth (Ingeborg Schöner), decide ayudarlo y le ofrece un rincón en el sótano de su edificio (cf. Ramírez Suárez 2013: 53:49). Sin una lengua común con la cual entenderse, Ruth y Ramón comienzan una amistad basada en la necesidad y la compasión, si no es que la lástima, 
comunicándose, de nueva cuenta, con gestos. Lo que esta breve sinópsis revela es que uno de los ejes de Guten Tag, Ramón es lo melodramático. El melodrama es generalmente asociado, como se comentaba con anterioridad, con lo sentimental y con la exageración, aunque en sus orígenes era considerado más que eso, como señala Ben Singer, pues incluía el exceso, sobre todo en la respuesta visceral del público ante espectáculos catastróficos o ante la injusticia moral. Linda Williams coincide con esta opinión. Para ella, aunque el melodrama se considera hoy como "a seemingly archaic excess of sensation and sentiment, a manipulation of the heart-strings that exceeds the bounds of good taste" (Williams 2001: 11), esta es una visión parcial del melodrama que excluye o relega a las orillas el exceso por considerarlo un género de aberración o de exageración histriónica. Lo que debe tenerse en cuenta, según ella, es que el melodrama, más que un género, es un modo de expresión artística que en gran medida define la cultura popular.

Estas observaciones sobre el melodrama son útiles al analizar la película Guten Tag, Ramón porque presenta este énfasis en lo sentimental y es un ejemplo de cultura popular, como lo demuestra su éxito en México, donde rompió récord de asistencia al ser proyectada en 250 salas nacionales y vista por más de un millón de personas, según Veronique Pugibet Ussel (cf. Pugibet Ussel 2018: 108-109). La pregunta consecuente sería, entonces, ¿por qué el melodrama tiene tal resonancia entre la gente del pueblo? En parte, como sugiere Williams, esto se debe a que hay una conexión entre modernidad y melodrama que tiene que ver con el percibido relativismo moral de la era moderna como constante fuente de tragedias. Singer coincide con Williams y lo resume así: "The popularity of melodrama [...] derived in part from its capacity to capture the sense of upheaval and vulnerability experienced by the masses in a world of unprecedented cultural discontinuity and social atomization" (Singer 2001: 294). Algo similar se puede decir del fenómeno de la migración, que en algunos casos sugiere una sensación de vulnerabilidad, de estar en una sociedad desintegrada y sin cohesión cultural. Y si bien es cierto que para muchos hoy en día el melodrama es algo anticuado y vergonzoso, algo que miraban los espectadores del pasado y, en su ingenuidad, disfrutaban, como señala Williams, la verdad es que el melodrama es fundamentalmente moderno, en cuanto que es una respuesta directa a "the normlessness of modernity [which] fostered a cycle of moral ambiguity, restless desire, frustration, and existential meaninglessness" (Singer 2001: 25).

El centro narrativo de la película es absolutamente sentimental y narra el desarrollo de la amistad entre el muchacho indocumentado y la anciana jubilada, la cual habrá de triunfar contra todo. Ramón comienza a hacer trabajos para los otros jubilados del edificio de esta, incluyendo clases de salsa, a cambio de un poco de dinero y sobre todo, de amistad. Ruth, en su papel de hada 
madrina, cubre las necesidades básicas de Ramón lo mejor que puede. Con esfuerzos, Ramón logra juntar dinero y enviárselo a su madre; la sentimentalidad de la suposición de que él está mejorando su situación o triunfando, sugerida por esta escena, es simplista, pues no toma en cuenta que el muchacho puede enviar dinero solo porque vive de gratis en el edificio de Ruth y a costas de ella. En una escena que muestra cómo han "mejorado" las cosas para Ramón, este habla con su amigo Güero para decirle que envió el dinero, y Güero le pregunta si todo está tan bien en Alemania como dicen, a lo que un sonriente Ramón responde que sí (cf. Ramírez Suárez 2013: 01:07:47) De esta manera, le miente a él, a sí mismo y a la audiencia, porque es Ruth quien lo mantiene y quien al final le deja como herencia una cantidad considerable de euros (cf. Ramírez Suárez 2013: 01:10:58), lo que, como apunta Pugibet Ussel, "le permitirá vivir un verdadero cuento de hadas, llevado a cabo en su propio país y junto a su familia a la que por fin podrá ayudar” (Pugibet Ussel 2018: 118).

Partiendo de ahí, la película presenta metafóricamente los problemas de México en un contexto de victimización, mientras que al mismo tiempo proyecta una imagen benevolente, generosa y liberal de Alemania. Con esto, no se quiere sugerir que la sociedad alemana no sea tolerante o generosa, ni que los problemas mexicanos se puedan explicar aislados de la economía mundial. No obstante, el gran defecto de la película es la falta de crítica al asumir que la sociedad alemana contemporánea es tolerante solo porque es próspera y que la mexicana está condenada al fracaso debido a la pobreza. Al final, Ramón "triunfa” no por mérito propio, ni por actos de justicia social, sino por la lástima de una mujer que vive en soledad y tiene los medios de ayudarle. Es sintomático, en este sentido, la falta de menciones a la situación alemana contemporánea, que incluye la migración desde África y Medio Oriente y el resurgimiento del neonazismo. Y es que como apunta Pugibet Ussel, "en un momento de crisis migratoria, el director opta por dar un mensaje humanista, utópico” (Pugibet Ussel 2018: 120).

A pesar de ese falso optimismo, no del todo ajeno al melodrama, que proclama que todo es cuestión de confiar en el amor o la mirada de lástima y benevolencia del otro, la película deja sus conflictos irresueltos y no ofrece nada al espectador, excepto una sensación de falso triunfalismo al sugerir que es solo cuestión de encontrar ancianos generosos, de sociedades prósperas que no tienen con quién compartir su vida y sus ahorros, y reunirlos con jóvenes de sociedades pobres. En ese sentido se trata de una película indulgente y falsa que manipula las emociones. Es esta falta de crítica lo que permite la perpetuación de los estereotipos y hace posible que en la imaginación popular europea se transfiera muy fácilmente la sensibilidad melodramática a las culturas latinas. La idea de que solo las culturas hispanas son melodramáticas tiene sin duda un trasfondo ideológico y no lógico que quiere "demostrar" su atraso, no solo 
económico sino emocional. Es obvio que se trata de una idea que busca enfatizar la diferencia de las culturas no centrales; luego, es evidente también que esta estrategia ha sido adaptada para excluirlas de la supuesta "madurez" de la cultural occidental. ${ }^{3}$

Pero si el director cae en esta trampa, esto no funciona igualmente desde la perspectiva del espectador. Y es que el público -todo público- es capaz de decodificar de manera sofisticada los melodramas tradicionales que le son presentados, simplemente porque no los toma literalmente o en serio; el público desde luego puede intuir ciertos usos subversivos del melodrama, pues no lo confunde con la realidad. El escapismo que se atribuye al melodrama no es más que otra manera de sublimación artística. El problema radica no en que los melodramas sean demasiado sentimentales, sino en que sean usados sin otro objeto que la manipulación sentimental con el fin de reforzar el status quo, en especial, las ideas más reaccionarias. El melodrama como manera de interpretar el mundo puede ser dinámico, pero requiere de la complicidad del público, y eso es algo que se ignora generalmente cuando se enfatiza lo sentimental del melodrama, mientras que el público es visto como una masa de ingenuos receptores pasivos a los que hay que proteger.

El melodrama, dice Linda Williams, es lo que describe el sentimiento de las obras que nos conmueven a todos, pero que no todos nos atrevemos a nombrar por miedo al desprestigio (cf. Williams 2001: 12). Sin embargo, en el fondo, melodrama es la palabra que mejor describe aquellas obras que provocan empatía con el sufrimiento de los otros, especialmente los desprotegidos. Es la mejor palabra para designar las narrativas populares de sentimientos nobles; el melodrama perdura, pues es un modo de contar historias y tejer narrativas, fundamental para establecer un consenso en lo que constituye el bien y la moral colectiva y su defensa, pues este -el término que mejor comprende tanto pathos como acción, según Williams- puede también canalizar el paroxismo del pathos en acciones concretas, centradas en la acción, el rescate, la persecusión y la lucha, etc. (cf. Williams 2001: 24). En otras palabras, la empatía del melodrama no es pasiva y puede ser un llamado a la acción.

3 La compleja relación del melodrama y las culturas latinoamericanas, particularmente en su forma contemporánea de telenovelas, y cómo es percibida es revisada por O. Hugo Benavides en Drugs, Thugs, and Divas: Telenovels and Narco-Dramas in Latin America, especialmente en el capítulo tres, "Producing the Global West through Latin Tales of Seduction and Envy" (cf. Benavides 2008: 46-66). 


\section{La mitología de los migrantes: Señales que precederán al fin del mundo}

A diferencia de Guten Tag, Ramón, la breve novela Señales que precederán al fin del mundo aborda el tema de la migración de manera compleja, apartándose de cualquier dualidad simplista, valiéndose de una reconfiguración del viaje de los migrantes de manera mitológica. La trama de esta novela es simple. Makina, una joven arriesgada y segura de sí, es enviada en busca de su hermano al otro lado de una frontera que podría ser la de México y Estados Unidos, aunque en la novela nunca se identifica como tal. Antes del viaje, la heroína busca la ayuda de personajes dudosos, identificados simplemente por una letra, el señor Q, el señor Dobleú, el señor Hache. Durante el viaje, pasa por una serie de aventuras; en algún momento encuentra a su hermano y no logra convencerlo de que regrese con ella; al final, ella misma decide no volver a su tierra, adoptando otra identidad. Este viaje va construyendo un recorrido por un espacio nuevo donde la frontera que hay que cruzar ya no es la división entre dos zonas geopolíticas, sino una división entre lo interior y lo exterior, lo individual y lo social, entre la realidad y el mito. Se trata de un viaje por el inframundo, en el que Makina ritualísticamente revive los pasos de los migrantes, convirtiéndose simbólicamente en la suma de todos ellos y de todas sus emociones. Como ha observado Martín Lombardo, el desplazamiento que atestiguamos en la novela "inaugura un nuevo espacio, un nuevo reparto de lo sensible con su correspondiente configuración comunitaria: un mundo de pasantes, de tráfico, de ilusiones y de represión" (Lombardo 2014: 205).

La novela hace evidente que uno de los momentos extremos en la vida de un individuo es el desplazamiento de una región a otra, cualquiera que sea la causa; sugiere asimismo que el fenómeno de la migración es antiguo y que se manifiesta de maneras variadas en diferentes épocas, o como lo resume Joseba Achotegui, "es un fenómeno tan viejo como la evolución o la humanidad [aunque] cada emigración posee características específicas” (Achotegui 2009: 166), pero a final de cuentas se trata de una misma historia. Es también un fenómeno mal entendido, como el mismo Achotegui afirma, pues el tema de la migración no ha sido estudiado completamente, a pesar de haber recibido atención por décadas, ya que se le ha mantenido circunscrito a las áreas económica y política, nunca a la psicológica o emocional. Tradicionalmente la migración ha sido analizada como un fenómeno colectivo y en menor medida personal, poniendo atención a sus consecuencias en la sociedad y rara vez en el ser humano. No se pretendía ir más allá de lo económico y lo político, centrándose en las razónes del desplazamiento (guerras civiles, pobreza, desastres naturales, etc.) y sus im- 
plicaciones para las sociedades que acogían a los desplazados (el cruce ilegal de fronteras, la crisis de refugiados, el costo al erario, el desempleo, etc.), minimizando las emociones, los sentimientos y las consecuencias psicológicas para las personas.

Esta manera parcial de abordar el fenómeno de la migración menoscababa o desdeñaba las experiencias personales y por consecuencia aminoraba sus implicaciones psicológicas, ignorando la manifestación emotiva. No es sino hasta muy recientemente que, en opinión de Achotegui, se ha comenzado a prestar atención al individuo y a tomar en cuenta de manera seria el aspecto emocional o psicológico de quienes migran. ${ }^{4}$ Es en este contexto en que debe leerse la novela de Yuri Herrera, quien no solo reconoce los aspectos emocionales de los migrantes, sino que va más allá al intentar conectar a las personas en un proceso que involucra aspectos sociales y emocionales, universalizados por medio de la mitología. Se trata de un intento por resolver el dilema entre lo interior y lo exterior, lo personal y lo social, superando la simplificación con la que generalmente se entiende la migración. La manera conciliatoria en la que Herrera usa la mitología es bastante similar a la manera en la que Robert Ellwood concibe la función de la mitología en la sociedad. Según él, el progreso social, y particularmente los retos de la modernidad, confrontaban a la humanidad con dos posibles formas de responder a estos problemas: una personal, a la manera de los gnósticos, quienes buscaban las respuestas dentro de sí mismos, y una colectiva, que buscaba respuestas en el mundo exterior, incluyendo la sociedad (cf. Ellwood 1999: 8-19).

Una tercera alternativa, que Ellwood reconoce y favorece, era recurrir a la mitología, ya que, se pregunta, qué otro tipo de conocimiento externo al hombre "could better be received and applied by modern humans than that contained in myth? It came from elsewhere, yet it did not require the difficult faith of dogmatic, exclusivist religion. It seemed rather, as packaged and interpreted by modern mythologists, to be universal and self-validating” (Ellwood 1999: 8). Esta tercera alternativa es la que vemos puesta en práctica en la novela. En ella, Herrera rechaza la idea de que el viaje individual, así como las cicatrices psicológicas y emocionales que deja en las personas, sea algo poco relevante. Más aún, rechaza la asunción, no pocas veces aceptada, de que la dureza del viaje fuera

\footnotetext{
4 El hecho de que esta visión ha cambiado lo demuestra el trabajo de un grupo de psiquiatras de la Universidad de Barcelona, quienes han propuesto un nuevo síndrome, el síndrome de Ulises, conocido también como la enfermedad del emigrante, para referirse a los estragos psicológicos que sufren los migrantes (cf. Achotegui 2009; Achotegui et al. 2015; Costa Pau 2002). La evocación de Ulises sugiere un viaje de peripecias y desventuras mil y apoya la utilidad del contexto mítico para referirse a los desplazamientos de los migrantes.
} 
positiva pues ponía a prueba la fortaleza de los migrantes, los que una vez reubicados en nuevas tierras, encontraban sus problemas resueltos. A esta visión parcial de la migración, Señales que precederán al fin del mundo opone una concepción que quiere ser completa por medio de un viaje mitológico. Esto es evidente desde la primera página, pues la novela comienza con un evento que Makina ve como una premonición: "el suelo se abrió bajo sus pies: se tragó al hombre, y con él un auto y un perro [...]. Estoy muerta, se dijo" (Herrera 2010: 11). Este carácter mítico es reforzado poco después con la descripción del viaje que hace el señor Q a la heroína, cuando le dice: "vas a cruzar y vas a mojarte y vas a rifártela contra gente cabrona; te desesperarás, cómo no, verás maravillas y al final encontrarás a tu hermano, y aunque estés triste llegarás a donde debes llegar” (Herrera 2010: 22).

Estas palabras, que resumen toda la trama de la novela, son proféticas. Así lo ve también Makina, quien reconoce su carácter enigmático, obligándola a detenerse "en el pasillo de espejos a pensar en lo que le había dicho el señor $\mathrm{Q}$ [ya que] era siempre como si brotaran piedras de su boca, aunque no supiera exactamente qué significaba cada una” (Herrera 2010: 23). En la novela hay desde el principio un reconocimiento del viaje y las emociones que este implica, y las palabras del señor Q son un reconocimiento de la complejidad de migrar, con sus triunfos y fracasos desde el sufrimiento del desplazarse hasta la posibilidad de ver maravillas, encontrar a los seres desaparecidos y llegar a donde se debe llegar. Señales que precederán al fin del mundo busca restablecer el balance entre el individuo y la colectividad por medio de la recreación mitológica, pues "[m]yth connects the self to society and world, unlike rationality, which depersonalizes and objectifies that which is other than self" (Ellwood 1999: 28). Para ello, se centra en el viaje migratorio y sus implicaciones para Makina, quien sale de su pueblo, llega a una gran ciudad, se desplaza a la frontera, la cruza ilegalmente y continúa su viaje en busca de su hermano. En el proceso nos damos cuenta de que ya no es simplemente ella, sino todos los migrantes.

La narración refiere las aventuras del desplazamiento, sin ignorar, desde luego, el aspecto psicológico y traumático de este, pero buscando siempre el balance entre lo individual y lo colectivo, valiéndose del mito como eje, particularmente del topos de la catábasis, revelado por el uso del concepto náhuatl del Mictlán, el inframundo en la cosmovisión mesoamericana. Cada uno de los nueve breves capítulos de la novela va marcando el desplazamiento de Makina, desde su pueblo hasta la región de los muertos, que vagamente se identifica con el norte. Cuando la muchacha explica al señor Dobleú que su madre la ha enviado a cumplir un encargo, para indicarle adónde, simplemente "señaló un punto cardinal” (Herrera 2010: 14). No hay ninguna razón en particular para suponer que señaló al norte, excepto que en la mitología azteca, el norte era el 
lugar donde se encontraba la entrada al inframundo, y todo parece sugerir que es adonde se dirige Makina, especialmente cuando nos damos cuenta de que cada uno de los capítulos de la novela se corresponde a las nueve regiones por donde deben pasar los muertos en su viaje por el Mictlán. Varios historiadores y cronistas, incluyendo al franciscano Bernardino de Sahagún, así como los códices Vaticano y Mayer, nos han dejado versiones de estas regiones o niveles del inframundo azteca; por estas fuentes sabemos que primero está el lugar donde corría un río que había que cruzar; luego seguía el lugar donde había que pasar entre dos cerros que chocaban entre sí; en seguida, el lugar del cerro cubierto de obsidiana; se seguía al lugar donde el viento cortaba como navaja; para pasar al lugar donde ondeaban las banderas; luego venía el lugar donde las fieras devoraban los corazones de los hombres; y en seguida estaba el lugar donde la culebra guardaba el camino; para llegar, finalmente, al lugar donde se encontraba la paz en Mictlantecuhtlui, el señor de la Muerte. ${ }^{5}$

Estas etapas del viaje al inframundo azteca se corresponden punto por punto con los capítulos de la novela de Herrera: "La tierra", "El pasadero de agua”, "El lugar donde se encuentran los cerros", "El cerro de obsidiana”, "El lugar donde el viento corta como navaja”, "El lugar donde tremolan las banderas", "El lugar donde son comidos los corazones de la gente", "La serpiente que aguarda" y "El sitio de obsidiana, donde no hay ventanas, ni orificios para el humo”. Es evidente que Herrera está insertando el viaje del migrante en un contexto mitológico. Para él es menos importante la realidad del viaje (adónde se va, cómo se va, adónde se llega, etc.), que demostrar que ese viaje es simbólico de un viaje que representa la confrontación de los problemas de la vida, o más aún, de un simbólico renacer. De ahí la decisión de nunca nombrar el lugar de origen y de destino, porque no es una novela sobre México y Estados Unidos, sino sobre el proceso de convertirse en un otro que habita una realidad nueva.

En el caso de esta novela, tanto Makina como su hermano deciden quedarse en el lugar al que emigran. Cuando finalmente se encuentran, él, con otro nombre, le explica a su hermana que una familia le pidió que asumiera la identidad de su hijo para que fuese enviado a la guerra en su lugar y "[a]l volver, la familia le pagaría una suma de dinero. Mucho dinero [...]. Además, podría quedarse

5 Las designaciones de los nueve niveles del inframundo y su descripción, así como la del Mictlán, varían a veces considerablemente. Sin embargo, hay elementos como los cerros que chocan, el cerro de pedernal de obsidiana, o el viento que corta como navajas, presente en todas las descripciones. Para la lista de este artículo se consideró la versión de Fray Bernardino de Sahagún y los códices Vaticano y Mayer, descritas sobre todo en Mendoza (1962), Johansson (2012) y Graulich (1989). 
con los papeles del hijo [y] sus números” (Herrera 2010: 98-99). Por su parte, Makina recibe una nueva identidad cuando un "hombre alto y delgado [de] dientes saltones [y] una sonrisa inmensa” (Herrera 2010: 118) le entrega una documentación, diciéndole que todo estaba arreglado. Ella "tomó el legajo y miró su contenido. Ahí estaba ella, con otro nombre y otra ciudad de nacimiento. Su foto, nuevos números, nuevo oficio, nuevo hogar” (Herrera 2010: 118-119). Pese a que al principio ella musita "[m]e han desollado" (Herrera 2010: 119), termina por aceptar el hecho, pues "entendió que lo que le sucedía no era un cataclismo; lo comprendió con todo el cuerpo y con toda su memoria” (Herrera 2010: 119). Y si esta pérdida de la identidad puede ser vista como un trauma, la verdad es que como señala Achotegui, "[1]a migración es muchas veces más una solución que un problema. Pero es una solución que encierra, a su vez, su parte de problema” (Achotegui 2009: 163).

En Señales, la experiencia de la migración está llena de negociaciones que tienen como objeto devolver la capacidad de acción a los migrantes, quienes deciden sobre su futuro aun si ello implica perder una identidad y ganar otra. Pero la novela también describe los problemas posteriores al viaje, como la ausencia de familia y amigos, el estar lejos de la tierra natal, la falta de contacto con la lengua, las costumbres o la religión; así como la falta de trabajo, la persecución policial, la explotación laboral o el rechazo racista que se sufre en la sociedad de acogida. Todo ello lo resume Herrera en el uso de la lengua, pues "en ella brota la nostalgia de la tierra que dejaron o no conocieron, cuando usan las palabras con que nombran los objetos” (Herrera 2010: 74). Más aún, cuando Makina es detenida con un grupo de inmigrantes por un policía racista, quien burlonamente le pide a uno de ellos que escriba, al darse cuenta que llevaba papel y lápiz, ella impulsivamente lo hace por él, a pesar de las protestas del policía, quien queda estupefacto y avergonzado al leer lo que ella escribe:

Nosotros somos los culpables de esta destrucción. Los que no hablamos su lengua ni sabemos estar en silencio. Los que no llegamos en barco [...] los que venimos a quitarles el trabajo, los que aspiramos a limpiar su mierda, los que anhelamos trabajar a deshoras. Los que llenamos de olor a comida sus calles [...]. Nosotros los oscuros, los chaparros, los grasientos, los mustios, los obesos, los anémicos. Nosotros los bárbaros. (Herrera 2010: 109-110)

El proceso de migrar es también un proceso de reeducación, de asimilación, como proclama el mismo policía dirigiéndose a los migrantes, a quienes les dice que si quieren venir a este nuevo lugar, si quieren ir al médico o hablar con alguien, se forman y piden permiso, pues, como afirma despectivo: “¡Así hacemos las cosas aquí, la gente civilizada! No brincándonos bardas ni ha- 
ciendo túneles" (Herrera 2010: 108). Aunque son muchas las adversidades a las que se enfrentan los migrantes, estas no siempre se superan. La verdad es que no todos logran sobreponerse a los cambios dolorosos o evolutivos que sufren, $y$ a veces su experiencia termina en catástrofe. Makina entiende que la transformación es el verdadero, y a veces doloroso, significado de la migración, ya que al final se convierte en tabula rasa, obteniendo así una oportunidad para recomenzar. Todo ello sucede en esta novela por medio de una revisión o reescritura de los textos míticos náhuas. Sin embargo, la recreación del viaje al inframundo de los textos sagrados precolombinos en Señales no es tanto una copia, como una guía; su originalidad proviene de su universalidad y su antigüedad. El tratarse de un texto mitológico ayuda a la heroína a convertirse en un intermediario entre el individuo y la sociedad. Al hacer este viaje, Makina se vuelve la heroína de todos, porque representa a todos: "The hero who transcends that collectivity must also be a part of it, so that it is the tribe's values that are made visible and timeless in the grand and authentic gestures of the hero" (Ellwood 1999: 29).

\section{Conclusión}

Como se arguyó al principio de este artículo, se pueden observar dos posiciones extremas al abordar el tema de la migración en la cultura mexicana: una sentimental y otra abstracta; la primera está ligada a prácticas discursivas y culturales tradicionales, como el melodrama, y la segunda utiliza la mitología para reelaborar el viaje de los migrantes de manera simbólica. La migración aludida aquí implica un desplazarse involuntario (por lo general en busca de oportunidades económicas), agravado por los obstáculos y peligros, ya sean geográficos, culturales, sociales o políticos, que tienen que hacer frente los migrantes y la conmoción, por las implicaciones emocionales y psicológicas derivadas de ello. Por lo tanto, también podemos hablar de un trauma, visto como ese acontecimiento o esos acontecimientos percibidos por un individuo como peligrosos y desestabilizadores (cf. Prager 2011: 429). Pero ese trauma también puede ser cultural, si es que los peligros son advertidos colectivamente como ataques a un grupo debido a su etnicidad, religión, "raza”, lengua o condición social, los cuales suelen dejar una marca negativa en la conciencia del grupo, a tal grado que pueden incluso alterar su sentido de identidad de manera considerable (cf. Alexander 2004: 1). Este es con frecuencia el caso de los migrantes, a quienes no es raro que se les acuse de intrusos y diferentes, es decir de no pertenecer.

Con todo, sería un error asumir que los migrantes solo pueden asumir un papel pasivo en este proceso, pues a menudo vemos estrategias personales y 
colectivas que buscan oponer y, si no invalidar, por lo menos negociar dichos traumas. Ya sea en el apelar a los otros para convencerlos de que se es digno de aceptación, por ejemplo usando el melodrama como un acto en el que se despliega el sufrimiento abnegado y virtuoso como el precio a pagar por la inclusión, como afirma Ana Elena Puga, para quien además, "suffering must be socially performed in order for it to be registered and responded to with empathy by audiences" (Puga 2012: 364). Estas audiencias pueden, a su vez, aceptar al otro o presionar para que se le acepte social y legalmente. De manera similar, el trauma cultural puede ser subvertido y reutilizado para dar cohesión al grupo y ayudarle a reafirmar su propia identidad a partir de la segregación sufrida: somos los otros, los que no hablamos su lengua, los que venimos de lejos, etc. Así, al recurrir a aspectos colectivos como la historia o la mitología se aborda la migración, no en términos específicos o sentimentales, sino como un fenómeno universal y ancestral que antecede a las leyes de exclusión de las naciones modernas, y por lo tanto, es un derecho inherente a todo ser humano, cuyo viaje al migrar se convierte en metáfora de otros viajes trascendentes o espirituales.

Dos obras que representan estas tendencias en la cultura mexicana son la película Guten Tag, Ramón y la novela Señales que precederán al fin del mundo. Mientras una manipula, hace una representación de los sentimientos, la otra ofrece como alternativa al migrante la posibilidad de ver su viaje como una liberación de la rigidez del ser y la posibilidad de conectarse con un pasado mítico y recrear así la propia identidad. Al colocar estas obras una frente a la otra, se observa un registro mucho más amplio de posibilidades para mirar, interpretar y renegociar el fenómeno de la migración, desarticulando el dilema entre lo interior y lo exterior, lo personal y lo social, permitiendo al individuo más posibilidades de involucrarse con el mundo y, a final de cuentas, transformarlo.

\section{Bibliografía}

Achotegui, Joseba (2009): “Migración y salud mental. El síndrome del inmigrante con estrés crónico y múltiple (síndrome de Ulises)”. En: Zerbitzuan 46, pp. 163-171.

Achotegui, Joseba et al. (2015): "Estudio sociodemográfico de los inmigrantes con síndrome de Ulises. Estudio sobre 1.110 inmigrantes atendidos en el SAPPIR en Barcelona”. En: Norte de Salud Mental 13.52, pp. 70-78.

Alexander, Jeffrey C. (2004): “Towards a Theory of Cultural Trauma”. En: Alexander, Jeffrey C. et al. (eds.): Cultural Trauma and Collective Identity. Berkeley: University of California Press, pp. 1-30.

Benavides, O. Hugo (2008): Drugs, Thugs, and Divas: Telenovelas and Narco-Dramas in Latin America. Austin: University of Texas Press. 
Brooks, Peter (1995): The Melodramatic Imagination. Balzac, Henry James, Melodrama, and the Mode of Excess. New Haven: Yale University Press.

Bruney, Gabrielle (2018): “Melania Trump Admitted that She Wore Her 'I Really Don't Care' Jacket to Send a Message”. En: Esquire. <https://www.esquire.com/news-politics /a23760074/melania-trump-i-really-don-t-care-jacket/> (16/09/2019).

Buen día, Ramón (13 de octubre de 2015): “Alguien en Boston que no haya visto \#buendiaramon \#gutentagramon. Hoy a las 7:30. Entrada libre”. En: Facebook <https://www.facebook.com/buendiaramon/> (16/06/2020).

Buen día, Ramón (25 de octubre de 2015): “El Greater Immigration FilmFest en Washington DC nos ha honrado con el premio a mejor película". En: Facebook <https://www.facebook. com/buendiaramon/> (16/06/2020).

Costa Pau, Marta (2002): "Síndrome de Ulises, la enfermedad del emigrante". En: El País <https://elpais.com/diario/2002/11/26/salud/1038265201_850215.html> (30/10/2019).

Dickerson, Caitlin (2018): "Hundreds of Immigrant Children Have Been Taken from Parents at U.S. Border”. En: The New York Times. <https://www.nytimes.com/2018/04/20/us/ immigrant-children-separation-ice.html (20/09/2019).

Ellwood, Robert (1999): The Politics of Myth. A Study of C. G. Jung, Mircea Eliade, and Joseph Campbell. New York: State University of New York Press.

Festival Internacional de Cine de Morelia (26 de octubre de 2013): "El estreno nacional del largometraje mexicano Guten Tag, Ramón dirigido por Jorge Ramírez-Suárez, se llevó a cabo en la edición número once del FICM”. En: Facebook <https://www.facebook.com/ moreliafilmfest/photos/a.145881754817/10151790801959818/?type=3> (16/06/2020).

Festival International du Film d'Amour - FIFA de Mons en Chile (20 de septiembre de 2015): “Guten Tag, Ramon” En: Facebook <https://www.facebook.com/fifamonschile/photos/ ms.c.eJw9zcENwDAIQ9GNKgTYsfdfrEppcnz6WHSBgmzT4Hr6s6Mq0hG ;tcZ1es39NXeXe8 yl8dlb4xxLufe5 _rh2Z ;z ;TWwjcU0WBL1gqyP5.bps.a.435685849969572/ 435688833302607> (16/06/2020).

Graulich, Michel (1989): “Miccailhuitl: The Aztec Festivals of the Deceased”. En: Numen 36.1, pp. 43-71.

Herrera, Yuri (2010): Señales que precederán al fin del mundo. Cáceres: Editorial Periférica. Johansson, Patrick (2012): “La muerte en la cosmovisión náhuatl prehispánica. Consideraciones heurísticas y epistemológicas”. En: Estudios de Cultura Náhuatl 43, pp. 48-93.

Latin American Film Festival Singapore (13 de noviembre de 2017): “Guten Tag, Ramón. Join us on December $10^{\text {th }} 2017,6: 45 \mathrm{pm}$ at the National Gallery!” En: Facebook <https://www.facebook.com/laffsingapore/posts/2001751923369552〉 (16/06/2020).

Lazar, Alon / Litvak-Hirsh, Tal (2009): “Cultural Trauma as a Potential Symbolic Boundary”. En: International Journal of Politics, Culture, and Society 22.2, pp. 183-190.

Lombardo, Martín (2014): “Autoridad, transgresión y frontera (sobre la narrativa de Yuri Herrera)”. En: Inti: Revista de literatura hispánica 79, pp. 193-214.

Mendoza, Vicente T. (1962): “El plano o mundo inferior. Mictlán, Xibalbá, Nith y Hel”. En: Estudios de Cultura Náhuatl 3, pp. 75-99.

Prager, Jeffrey (2011): “Danger and Deformation: A Social Theory of Trauma Part I: Contemporary Psychoanalysis, Contemporary Social Theory, and Healthy Selves”. En: American Imago 68.3, pp. 425-448.

Puga, Ana Elena (2012): “Migrant Melodrama and Elvira Arellano”. En: Latino Studies 10.3, pp. 355-384. 
Pugibet Ussel, Veronique (2018): “Los estereotipos nacionales como resortes de dos comedias comerciales: Guten Tag, Ramón y Perdiendo el Norte”. En: Comunicación Social 32, pp. 103-124.

Ramírez Suárez, Jorge (2013): Guten Tag, Ramón. México / Alemania: Beanca Films / MPN Cologne Film 3 / FOX International Productions / FIDECINE.

Schmidt, Samantha (2018): "Rachel Maddow Breaks Down in Tears on Air While Reading Report on 'Tender Age' Shelters”. En: Chicago Tribune <https://www.chicagotribune. com/entertainment/tv/ct-rachel-maddow-crying-on-air-20180620-story.html> (14/06/ 2020).

Singer, Ben (2001): Melodrama and Modernity. Early Sensational Cinema and its Contexts. New York: Columbia University Press.

Williams, Linda (2001): Playing the Race Card. Melodramas of Black and White from Uncle Tom to O. J. Simpson. Princeton: Princeton University Press. 